\title{
O protagonismo do Grupo de Valorização Negra do Cariri no enfrentamento à violência doméstica e familiar contra a negritude feminina do município de Crato- $\mathrm{Ce}$
}

The protagonism of Cariri Black Valorization Group in facing domestic and family violence against the female blackness of the municipality of Crato-Ce

\author{
Liliane Matias da Silva ${ }^{1}$ \\ Felipe Silva Duarte ${ }^{2}$ \\ Joseane de Queiroz Vieira ${ }^{3}$
}

\begin{abstract}
RESUMO
O objetivo desta pesquisa foi examinar a participação do Grupo de Valorização Negra do Cariri no combate à violência doméstica contra a mulher negra em Crato, interior do Ceará. Verificou-se que essa associação civil é um modelo de enfrentamento à violência de raça e de gênero, perante a negligência histórico-estatal.
\end{abstract}

PALAVRAS-CHAVE: Grupo de Valorização Negra do Cariri. Mulher negra. Violência doméstica e familiar.

\begin{abstract}
The aim of this research was to examine the participation of Cariri Black Valorization Group in the combat against domestic violence against black women in Crato, interior city of Ceará. It was verified that this civil association is a model of confrontation to the violence of race and gender, before historical state disregard.
\end{abstract}

KEYWORDS: Cariri Black Valorization Group. Black Woman. Domestic and family violence.

\footnotetext{
${ }^{1}$ Universidade Regional do Cariri. E-mail: Lili_matias_07@hotmail.com.

${ }^{2}$ Universidade Regional do Cariri.

${ }^{3}$ Professora em membro do Núcleo Docente Estruturante - NDE do Curso de Direito do Centro Universitário Dr. Leão Sampaio - UNILEÂO e Coordenadora do Curso de Direito da Faculdade Vale do Salgado - FVS.
} 


\section{Introdução}

Enquanto sujeito social, a mulher negra tem figurado nas páginas da história brasileira como alvo do vultoso panorama de violência em desfavor de sua integridade física, moral e psíquica. Em se tratando do contexto atual, esse cenário de agressão persiste ao passo em que as estatísticas nacionais revelam que a feminidade afrodescendente continua sendo aquela que mais sofre com a violência, principalmente no âmbito doméstico e familiar.

Ao se debruçar sobre o município de Crato, situado no sul do Estado do Ceará, percebe-se que o fenômeno de violência contra a mulher negra é muito atrelado à desconsideração que o Poder Público e que a história vêm atribuindo a essas vítimas.

Dessa forma, perante a negligência histórico-científica e estatal, coube à própria comunidade negra do Crato-CE a iniciativa de se mobilizar através de movimentos sociais com o fito de buscar a valorização da afrodescendência e tentar expor a tamanha vulnerabilidade que a mulher negra cratense sofre em seus lares.

Nesse sentindo, uma das organizações civis que mais se destaca no município em questão é o Grupo de Valorização Negra do Cariri GRUNEC, pessoa jurídica de direito privado sem fins lucrativos, cujo objetivo principal é promover o enaltecimento da etnia negra dos habitantes do sul do Estado do Ceará e, consequentemente, enfrentar as mais diversas formas de violências às quais essa população é submetida.

Esse Grupo, apesar de décadas de militância, ganhou grande evidência em 2016, ano em que a violência de gênero e de raça ocupou o ápice das discussões nos contornos do Ceará, fazendo com que as articulações do GRUNEC se encaminhassem em direção ao enfretamento desse tipo de violação de direitos.

É diante dessa conjuntura que esta pesquisa apresenta como temática o protagonismo do Grupo de Valorização Negra do Cariri 
(GRUNEC) no enfrentamento à violência doméstica e familiar contra a negritude feminina no município de Crato-CE no ano de 2016. Partindo deste tema, a indagação fundante para a construção da problemática consiste em saber de que forma o GRUNEC, enquanto movimento social negro, se articulou para o enfrentamento da violência doméstica familiar contra a negritude feminina cratense no ano de 2016. Neste sentido, o objetivo geral desta pesquisa foi examinar a participação do Grupo de Valorização Negra do Cariri no combate à violência doméstica e familiar contra a negritude feminina na urbe de Crato-CE no ano de 2016.

Para tanto, seus objetivos específicos foram: I) compreender como a questão de gênero e de raça atua como duplo fator de vulnerabilidade em desfavor das mulheres negras no ambiente doméstico; II) buscar dispositivos legais que visam resguardar o direito da feminidade afrodescendente de viver em um espaço familiar livre de atentados violentos; III) estudar a forma de participação dos movimentos sociais no enfrentamento a essa forma de violência; IV) investigar como ocorreu a atuação do GRUNEC no enfretamento a esse problema no município de Crato-CE em 2016.

Ademais, a metodologia aplicada foi a indutiva, pois analisou a realidade de um grupo de temática negra do município do Crato-CE no combate à violência contra a negritude feminina para, em seguida, refletir sobre a participação dos movimentos sociais negros no enfrentamento à violência de gênero e de raça. Neste sentido, a pesquisa adotou uma abordagem essencialmente qualitativa de caráter descritivo e explicativo da realidade a ser investigada.

Para coleta de dados, além dos procedimentos atinentes ao estudo bibliográfico (pesquisa em livros, dissertações, teses e artigos de periódicos científicos, disponíveis em bibliotecas físicas e banco de dados virtuais), foi realizado estudo de campo no Grupo de Valorização Negra do Cariri consistente na visita à sede do mesmo com dois objetivos: 1) realizar uma pesquisa documental no estatuto do GRUNEC; 2) efetuar entrevista 
semiestruturada do tipo focalizada com os membros efetivos e dirigentes do Grupo. Frisa-se que ambos os procedimentos foram efetuados após apreciação e aprovação do Comitê de Ética em Pesquisa, conforme parecer disponível na Plataforma Brasil.

Assim, a relevância da presente pesquisa correspondeu ao fato de que, apesar de a violência doméstica e familiar contra a mulher negra ser persistente e crescente no cenário brasileiro, a comunidade científica pouco desenvolve esse recorte racial, analisando o fenômeno da violência contra a mulher apenas sob seus aspectos gerais, e, consequentemente, desconsidera as peculiaridades das relações de violência contra a mulher negra.

Espera-se ainda que o estudo aqui apresentado contribua para alertar o Poder Público e a população - a priori do município de Crato-CE e a posteriori de qualquer localidade do Brasil - de que as relações privadas abrigam um contexto de violência em desfavor das mulheres, em especial, de cor preta e parda, o que requer atenção e fortalecimento das políticas de enfretamento desta realidade.

\section{Gênero e raça/cor enquanto fenômenos de subordinação e de violência}

O presente trabalho, como já afirmado, faz estudos acerca da violência contra a mulher negra na região sul do Estado do Ceará no ano de 2016, o que mostra o quanto esse tema é atual. No entanto, a atualidade temática apontada não quer significar que não exista uma longa história de violações de direitos que se apresenta como influenciadora da realidade presente. Dessa forma, é necessário compreender toda a historicidade por trás da noção atual acerca da raça negra e do gênero feminino, para, assim, mostrar como ser uma mulher e, ainda, ser negra é carregar um estereótipo pré-determinado constituído historicamente na sociedade, proporcionandolhe extrema vulnerabilidade, inclusive no meio doméstico. 


\subsection{Aspecto histórico do "ser negra"}

É interessante observar que um país como o Brasil, o qual possui a maior parte de sua população como parda e preta, tendo seu povo sido fruto da miscigenação de diferentes raças, ainda possui elevados níveis de preconceito e de discriminação racial. Assim, é mister expor inicialmente, mesmo que de forma breve, o desenvolvimento do racismo no mundo para, a posteriori, se ater à nação em estudo. Focando na discriminação racial baseada na cor da pele, observa-se que

Em todos os tempos esta cor sempre esteve revestida de valores negativos nas línguas indo-europeias. É desta maneira que em sânscrito, o branco simboliza a classe dos brâmanes, a mais elevada da sociedade. Em grego, o negro sugere uma macula, tanto moral quanto física; ele trai, igualmente, os homens de intenções sinistras. Os romanos não somaram a este vocábulo nenhum significa novo: para eles, o negro é signo de morte e de corrupção enquanto o branco representa a vida e a pureza. Os homens da igreja, à procura de chaves e de símbolos que revelassem os sentidos ocultos da natureza, fizeram do negro a representação do pecado e da maldição divina (COHEN, 1980, p. 39 apud SANTOS, 2005, p. 45).

Dessa forma, antes mesmo que houvesse a ideia de separar grupos por meio de sua raça, a cor negra já simbolizava ideias negativas. Neste sentido, Santos (2005, p. 27) expõe que com os iluministas a ideia de raça era similar a linhagem, na própria história das raças, no entanto, já era possível perceber um tratamento diferenciado com relação ao negro. Assim, no Tratado de Metafísica do iluminista Jean Marie Arouet, Conde de Voltaire, este apresenta as noções que um viajante interplanetário teria ao encontra o primeiro ser humano.

Segundo a narrativa, o viajante desembarca no oceano, no país da Cafraria e começa a procurar o homem. Assim, ele começa a descrever o que vê, citando: macacos, elefantes e negros, sendo estes últimos apresentados nos seguintes termos: 
Um animal preto, que possui lã sobre a cabeça, caminha sobre duas patas, é quase tão destro quanto um símio, é menos forte que os outros animais de seu tamanho, provido de um pouco mais de idéias do que eles e dotado de maior facilidade de expressão. Ademais, está submetido às mesmas necessidades que os outros, nascendo, vivendo e morrendo exatamente como eles (VOLTAIRE, 1978b, p. 62 apud SANTOS, 2005, p. 27).

O viajante após observar as diversas espécies de animais, e ver que o negro, ainda que no final das contas, apresentava um grau mínimo de superioridade em relação aos bichos, consegue concluir que o negro seria o homem.

Deste modo, é no século XIX que a ideia de raça começa a mudar de sentido, passando a definir e separar grupos humanos. Destarte, é com o darwinismo que a questão de raça se tornou mais radical, pois com base nos princípios da evolução, haveria de ter uma raça superior, pura e, consequentemente, uma raça inferior e mais frágil. A raça negra foi eleita como a inferior, pois biologicamente seu crânio era menor (ora se o cérebro é o órgão mais importante do corpo humano, seu formato conseguiria determinar as qualidades de cada indivíduo), além do pouco desenvolvimento de suas sociedades (SANTOS, 2005, p. 51).

Conforme Santos (2005, p. 52), não demorou para que os darwinistas estimulassem o preconceito racial como forma de eugenia, procurando evitar a mistura da raça superior com a inferior. Deste modo, a ciência passou a se tornar uma justificação para a dominação de uma raça sobre a outra.

Reportando-se ao contexto brasileiro, tem-se que entre os séculos XVI e XIX o país escravizou homens e mulheres africanos. Essas pessoas eram tratadas como animais, vinham para o território brasileiro em embarcações com condições insalubres, ao chegar, continuavam vivendo em locais inadequados e seu cotidiano era marcado pela violência. 
Consoante Abdias do Nascimento (1978, p. 48), com a descoberta do Brasil pelos portugueses em 1500, e sua consequente exploração, iniciouse imediatamente o surgimento da raça negra "fertilizando o solo brasileiro com suas lágrimas, seu sangue, seu suor e seu martírio na escravidão”.

O papel do escravo negro foi decisivo para os começos da história econômica de um país fundado, como era o caso do Brasil, sob o signo do parasitismo imperialista. Sem o escravo a estrutura econômica do país jamais teria existido. O africano escravizado construiu as fundações da nova sociedade com a flexão e a quebra de sua espinha dorsal, quando ao mesmo tempo seu trabalho significava a própria espinha dorsal daquela colônia. Ele plantou, alimentou e colheu a riqueza material do país para o desfrute exclusivo da aristocracia branca (NASCIMENTO, A., 1978, p.49).

Desse modo, apesar de ser a classe rejeitada, era o trabalho escravo que desenvolvia a economia do país.

Já no século XIX, segundo Santos (2005, p. 80) com as grandes nações europeias se desenvolvendo com ideais liberalistas, muitos pensadores começaram a criticar o sistema escravista brasileiro tentando seguir o exemplo de nações independentes e promover o desenvolvimento da sua população. Este desenvolvimento não ocorreria em um país em que escravos e seus senhores se encontravam em patamares diferentes, sendo necessário, para tanto, a abolição da escravidão no Brasil. Além disso, havia o temor do surgimento de revoltas maiores dos negros, e que estes tomassem o poder. Destarte, a abolição foi mais uma forma de afirmar a supremacia dos brancos, já que com ela o negro passou a ser visto como o "cidadão indesejado, cidadão por acaso, por força e vontade branca [...]" (SANTOS, 2005, p. 132).

Após a abolição surgiram ainda mais ideias racistas em relação aos afrodescendentes. Ao passo em que o processo abolicionista ocorria, o Brasil começou a atrair mão de obra imigrante europeia, que, apesar desta ser mais cara do que a negra, trazia algo almejado pela civilização da época: o 
"embranquecimento" da população. Assim, nessa realidade os imigrantes começaram a se desenvolver no país, o que, devido ao racismo, não acontecia com os negros, proporcionando ideias em relação a estes como preguiçosos e ignorantes. "Somando-se um mito após o outro, inferioridade, vagabundagem, incompetência, foi-se esboçando o perfil do homem negro, como anticidadão, como marginal.”. (SANTOS, 2005, p. 119). Assim, a rejeição aos negros só aumentava após a abolição da escravidão.

\subsection{Aspectos históricos acerca do gênero feminino}

Traçar uma linha histórica do papel feminino na sociedade desde o surgimento da humanidade é uma tarefa difícil, uma vez que a mulher, em que pese as variações históricas e culturais dos povos, de modo geral não tinha papel de destaque ou relevância na história escrita e transmitida ao longo do tempo, a mulher não era vista como importante, na realidade, nem era vista. Assim, pouco foi registrado sobre a função da mulher além da de gerar filhos e cuidar do lar.

Antes de adentrar em assunto tão delicado, é necessário afirmar que o presente estudo não visa questionar ou ofender nenhum tipo de crença. No entanto, como uma análise, se torna essencial expor determinados fatos relevantes para tal tema. Assim, no princípio, conforme a civilização judaico-cristã, a mulher haveria surgido a partir de um homem, enquanto este foi produto da vontade sagrada, sem nenhuma interferência feminina. Com isso, a mulher teria uma diferença em relação ao ser masculino, uma vez que não seria fruto exclusivamente do desejo divino, mas em sua composição carregava uma parte do homem (WALLER, 2008, p. 18).

Seguindo ainda o livro de Gênesis, Eliane Waller (2008, p. 19) explana a tão conhecida história sobre a culpa original em que a serpente engana a mulher afirmando que o fruto da árvore que o Senhor havia proibido Eva e Adão de comerem sob pena de morrerem, na realidade, os tornariam como deuses, conhecedores do bem e do mal. Eva, então, come e 
oferece a Adão. Como consequência, ambos são expulsos do paraíso, mas à mulher, Deus disse: "Multiplicareis os sofrimentos de teu parto; darás à luz com dores, teus desejos te impeliram para o teu marido e tu estarás sob o seu domínio" (Gênesis 3:16 apud WALLER, 2008, p. 19).

A mitologia grega também traz contribuições para a história da mulher, outra história bem conhecia é a da "caixa de Pandora". Segundo Eliane Waller (2008, p. 19-20) citando Junito de Souza Brandão (1993, p. 168), um dos titãs, chamado Prometeu, escalou o Olimpo e roubou o fogo divino, o que fez com que Zeus ficasse embravecido. Diante disso, Zeus amarra Prometeu em um rochedo e diariamente um abutre vem comer seu fígado, que se regenera durante a noite para que no outro dia o abutre volte a comê-lo. Zeus, ainda não satisfeito, faz descer à terra uma mulher muito bonita carregando uma caixa ornamentada de marfim, com a orientação de que essa caixa deveria ser oferecida ao seu marido como seu dote e só poderia ser aberta após o casamento. Pandora casa-se com Epimeteu, irmão de Prometeu, sentindo-se sozinha e curiosa, abre a caixa, deixando escapar todos os males do mundo, como: inveja, ódio, ambição. Dessa forma, conforme Eliane Waller (2008, p. 20) "inevitavelmente, a carga pejorativa recaiu sobre a curiosidade de Pandora, que se associou à imagem feminina".

É a partir de crenças como essas acima narradas que ao longo da história é construída uma carga de personalidade equivocada e préestabelecida acerca da mulher. No entanto, há bem mais que as apresentadas até agora. A autora Eliane Waller (2008, p. 21), ensina que a partir do século XII, a mulher passa a ser vista como um ser pecaminoso, o que designaria aos padres e aos maridos o dever de orientálas, se necessário até pela força, para seguir o bem, ou mais claro, o caminho que eles determinassem para elas.

Recorrendo a Emanuel Araújo (2004, p. 46), Eliane Waller (2008, p. 21) expõe que a mulher também era vista como feiticeira, pois se imaginava que o ser feminino buscava esses meios para se tornar bela ou para reduzir 
a potência sexual dos homens, relegando-os a uma situação desonrosa. Desse modo, acerca da figura feminina passa a pairar um estereótipo de seres problemáticos, que deveriam ser observados, controlados ou, até mesmo, exterminados.

Ainda consoante Eliane Waller (2008, p. 21) mencionando Araújo (2004, p. 46), voltando à história do "pecado original", como o primeiro contato que a serpente tem é com a mulher, é incutido na natureza feminina algo como um estigma hereditário que a predispunha à transgressão. Com base nisso, o ser masculino representava a Igreja dentro da casa, e a mulher simbolizava o pecado de Eva. Nesse diapasão, "Já que a mulher partilhava da essência de Eva, tinha de ser permanentemente controlada" (ARAÚJO, 2004, p. 46 apud WALLER, 2008, p. 21).

No século XVI, época em que ocorre o descobrimento do Brasil, os europeus, ao chegarem ao território brasileiro e observarem os costumes dos nativos, perceberam a pouca rigidez em suas relações de parentesco, por exemplo, um tio podia casar-se com sua sobrinha (PRIORE; BASSANEZI, 2004, p.18). Apesar disso, nas sociedades indígenas, o tratamento com as mulheres não era tão diferente em relação ao dos europeus. Conforme Mary Del Priore e Carla Bassanezi (2004, p.19), em terras desconhecidas, os índios andavam na frente de suas esposas para protegê-las, entretanto, nas terras seguras, as mulheres iam na frente para serem observadas por seus parceiros.

Ao passo em que se intensifica a vinda de europeus para o Brasil e a colônia começa a se desenvolver economicamente, a figura da mulher estagna no tempo, pois ainda é considerada um ser imperfeito que necessita sempre de estar vigiada. É dessa forma que somente em 1827 ocorre um significativo avanço, surge a primeira lei sobre os direitos das mulheres no Brasil, esta lei permitia que meninas frequentassem instituições de ensino elementar, e em 1879 as mulheres conseguem autorização para estudar em escolas de ensino superior (COIMBRA, 2011, p. 18). Assim, mesmo que com 
grandes obstáculos, a história dos direitos femininos começa a ser traçada no Brasil.

\subsection{Ser mulher e ser negra como fator de vulnerabilidade no meio doméstico}

Com base no que foi até agora apresentado, uma breve análise da história permite afirmar que as pessoas de gênero feminino e as pertencentes à raça negra costumeiramente ocuparam posição de submissão frente ao homem branco. Logo, os indivíduos que carregam esses dois fatores - ser do sexo feminino e ser da raça negra - encontram-se ainda mais subordinados aos desejos da sociedade, resultando no fato de que a feminitude afrodescendente precisa superar mais dificuldades e preconceitos que a mulher branca. Sobre o racismo contra as mulheres negras nas sociedades coloniais convém destacar que:

[...] estudos comprovam que os gestos mais diretos e a linguagem mais chula eram reservados a negras escravas e forras ou mulatas; às brancas se direcionavam galanteios e palavras amorosas. Os convites diretos para fornicação eram feitos predominantemente às negras e pardas, fossem escravas ou forras. Afinal, a misoginia - ódio das mulheres racista da sociedade colonial as classificava como fáceis, alvos naturais de investidas sexuais, com quem se podia ir direto ao assunto sem causar melindres. O ditado popular parecia se confirmar: "Branca para casar, mulata para foder e negra para trabalhar" (PRIORI, 2013, p. 24).

Assim, a hipererotização da mulher afrodescendente, desde a época colonial também contribuiu para a crescente violência, uma vez que elas continuam sendo tratadas e vistas como objetos. Sueli Carneiro (2003, p. 49), fundadora e coordenadora-executiva do Géledes - Instituto da Mulher Negra com sede em São Paulo -, apresenta que sobre a mulher afrodescendente, recai a carga da herança colonial, época em que o regime patriarcal sustentou-se sobre a superioridade masculina branca em uma ordem de mais valia, que seria: “o poder político econômico, social e cultural 
é privilégio do homem branco; logo depois, numa degradação de valor da mulher branca, e abaixo desta, o homem negro”. Seguindo esta escala, a mulher negra se encontrava em último, como parte mais desvalorizada da população brasileira.

Dessa forma, além da mulher carregar consigo o estereótipo social de ser considerada o sexo frágil, imperfeito e que necessita do cuidado do homem, a realidade de mulher negra apresenta ainda outras características:

Quando falamos do mito da fragilidade feminina, que justificou historicamente a proteção paternalista dos homens sobre as mulheres, de que mulheres estão falando? Nós, mulheres negras, fazemos parte de um contingente de mulheres, provavelmente majoritário, que nunca reconheceram em si mesmas esse mito, porque nunca fomos tratadas como frágeis. Fazemos parte de um contingente de mulheres que trabalharam durante séculos como escravas nas lavouras ou nas ruas, como vendedoras, quituteiras, prostitutas... Mulheres que não entenderam nada quando as feministas disseram que as mulheres deveriam ganhar as ruas e trabalhar! Fazemos parte de um contingente de mulheres com identidade de objeto. Ontem, a serviço de frágeis sinhazinhas e de senhores de engenho tarados. Hoje, empregadas domésticas de mulheres liberadas e dondocas, ou de mulatas tipo exportação (CARNEIRO, 2003, p. 49).

Desta feita, a negritude feminina constitui a parcela da sociedade que sofre duplamente por ser o que é. Assim, é inegável que as mulheres brancas também sofrem violência de gênero, entretanto, as negras sofrem em proporções desiguais devido a discriminação racial a que também estão sujeitas.

Consoante o que já foi analisado, como herança histórica, econômica e social, a população afrodescendente precisa contornar obstáculos maiores que a branca. Em meados do século XIX, enquanto o europeu estava se desenvolvendo no Brasil, o negro estava estagnado. Assim, começar a se desenvolver em um país que há pouco tempo havia abolido a escravidão e 
que sua economia já estava se desenvolvendo, não era tarefa fácil para um negro.

Esse contexto reflete na atualidade, pois, em 2016, segundo o Instituto Brasileiro de Geografia e Estatísticas - IBGE (2017, p.65) ao detalhar a população com renda abaixo da linha de 5,5 dólares por dia, a pobreza monetária atinge mais homens e mulheres pretas ou pardas, sendo respectivamente $33,3 \%$ e $34,3 \%$, contra cerca de $15,0 \%$ para homens e mulheres brancas.

Convém destacar que junto com a pouca renda está associada a baixa escolaridade. Desse modo, as mulheres que tradicionalmente já eram designadas às atividades do lar, não são estimuladas ao estudo, apresentando pouca expectativa de mudanças em sua realidade, continuando somente no ambiente doméstico, tendo filhos e cuidando do lar. E é exatamente nesse ambiente doméstico que geralmente ocorre a violência de gênero. Se para as mulheres brancas já é difícil se desligar do lar, para a negra é ainda mais, uma vez que poucas possuem escolaridade para se sustentarem sem o marido, ou mesmo consideram aceitável sofrerem abusos devido a suas raízes históricas.

\section{A violência doméstica e familiar contra a mulher negra sob o amparo da Lei Maria da Penha}

Era de ser natural que o meio doméstico fosse um lugar seguro e acolhedor, ora, onde mais um indivíduo estaria protegido do que em seu próprio lar? Entretanto, para algumas mulheres tal sentimento é inexistente, pois para elas a segurança a qual acreditam possuir é violada por alguém com quem convivem. Situações como estas levam Heleieth Saffioti (2009, p. 27) a afirmar que o domicílio não é o local para a mulher exercer seu direito à privacidade, mas é na realidade o lugar da violência doméstica. Assim, o direito a um espaço da intimidade é assegurado apenas aos homens. 
Gláucia Fontes (2010, p. 02) leciona que a violência de gênero pode ser justificada como uma questão cultural, em que a sociedade incentiva os homens a realizarem sua força de dominação e potência sobre as mulheres. Nesse diapasão, a violência na modalidade ora estudada, ocorre como reação daquele que pensa ser possuidor da vítima, o que não se verifica apenas em razão do relacionamento sexual, mas também do fator econômico, uma vez que, geralmente, o homem é quem sustenta a mulher.

Esse contexto de violência de gênero frente à inércia estatal em combatê-la, levou a Comissão Interamericana de Direitos Humanos, com base no caso da Maria da Penha, a sugerir que o Brasil criasse políticas públicas de enfrentamento à violência contra a mulher. Deste modo, o Brasil em 07 de agosto de 2006 insere em seu arcabouço jurídico a Lei 11.340 (também denominada de "Lei Maria da Penha"), a qual, segundo Piovesan e Pimentel (2011, p. 112), gera, de forma inédita, meios com a finalidade de frear a violência doméstica e familiar contra a mulher, definindo medidas para prevenção, assistência e proteção à feminitude que sofre violência.

É mister apresentar que até a criação da Lei 11.340/06 o direito brasileiro não reconhecia a gravidade de tais crimes em estudo. Assim, recorrendo novamente à Piovesan e Pimentel (2011, p. 122), era aplicada a Lei 9099/95 que tratava especificamente das infrações penais de menor potencial ofensivo, isto é, as consideradas de menor gravidade em que a pena máxima definida em lei não ultrapassasse um ano. Desta maneira, até 2006, a falta de amparo legal satisfatório com a aplicação da Lei 9099/95 proporcionou a legitimação e a naturalização da violência contra a mulher.

Como todas as lutas para a obtenção de direitos e proteção às mulheres não foram simples, o surgimento da Lei Maria da Penha também não haveria de ter sido. A própria lei traz o nome de uma vítima da violência doméstica, Maria da Penha, a qual sofreu duas tentativas de homicídio, agressões estas que resultaram em deixá-la paraplégica aos 38 
anos, foram cometidas por seu então companheiro, em seu próprio domicílio, na cidade de Fortaleza, em 1983, conforme Piovesan e Pimentel (2011, p. 109).

Apesar de condenado pela Justiça local, após quinze anos o réu ainda permanecia em liberdade, valendo-se de sucessivos recursos processuais contra decisão condenatória do Tribunal do Júri. A impunidade e a inefetividade do sistema judicial frente à violência doméstica contra as mulheres no Brasil motivou, em 1998, a apresentação do caso à Comissão Interamericana de Direitos Humanos (OEA), por meio de petição conjunta das entidades CEJIL-Brasil (Centro para a Justiça e o Direito Internacional) e CLADEM-Brasil (Comitê Latino-Americano e do Caribe para a Defesa dos Direitos da Mulher). Em 2001, após 18 anos da prática do crime, em decisão inédita, a Comissão Interamericana condenou o Estado brasileiro por negligência e omissão em relação à violência doméstica (PIOVESAN; PIMENTEL, 2011, p. 109).

Nesse diapasão, o caso de violência sofrida por Maria da Penha conseguiu exprimir internacionalmente a indiferença com que o direito brasileiro tratava a violência doméstica. Analisando a Lei 11.340/06 sob o enfoque deste trabalho, pode-se afirmar que ela é mais necessária para as mulheres negras do que para as mulheres brancas, à medida que as maiores vítimas da violência doméstica e familiar são as mulheres negras, de tal sorte que são essas que mais se beneficiam dos instrumentos protetivos da Lei Maria da Penha.

Deste modo, segundo balanço do primeiro semestre de 2016 da Secretaria Especial de Políticas para as Mulheres do Ministério da Justiça e Cidadania, dos 555.634 atendimentos realizados naquele período nos que foram informados a cor da vítima, 59, 71\% das violências foram cometidas contra mulheres negras e 39,28\% foram contra mulheres brancas. Tais dados mostram como a feminitude afrodescendente precisa da proteção legislativa para o enfrentamento da violência em que são vítimas. 


\section{A pertinência das organizações civis no enfrentamento à violação de direitos da feminitude afrodescendente}

Com base no exposto até esta seção é de se esperar que um povo que precisou lutar desde o início de sua escravização, também necessitasse de ter forças para se defender contra as desigualdades que sofrem ao longo de sua história. É deste modo que surgem as organizações compostas por indivíduos com o objetivo de combater o racismo e as desigualdades sofridas pelos afrodescendentes. Destarte, é possível afirmar que tais organizações atuam como movimento social, este

[...] diz respeito aos processos não institucionalizados e aos grupos que os desencadeiam, às lutas políticas, às organizações e discursos dos líderes e seguidores que se formam com a finalidade de mudar, de modo frequentemente radical, a distribuição vigente das recompensas e sanções sociais, as formas de interação individual e os grandes ideais culturais (ALEXANDER, 1998, p. 01 apud PEREIRA, 2010, 81).

Reportando-se ao movimento social negro no Brasil, é possível afirmar que este existe desde a chegada dos primeiros africanos à terra brasileira, conforme Abdias do Nascimento (2000, p. 204) citado por Amilcar Araujo Pereira (2010, p. 142), "não existe o Brasil sem o africano, nem existe o africano no Brasil sem o seu protagonismo de luta antiescravista e anti-racista". Ademais, as rebeliões de escravos e o surgimento dos quilombos comprovam a resistência à opressão e à exploração, segundo Sérgio Costa (2006, p. 83) citado por Pereira (2010, p. 83).

Consoante Andrews (1998, p. 227) citado por Pereira (2010, p. 86-87) uma das entidades mais conhecidas em São Paulo e que merece destaque no presente estudo foi o Centro Cívico Palmares, que teria sido um marco importante para a mobilização dos negros no Estado Paulista, foi fundado em 1926, período que antecede a Revolução de 1930. O Centro Cívico Palmares contribui significativamente para o posterior surgimento da Frente Negra Brasileira - FNB, em 1931. Deste modo, ainda em 
concordância com o mesmo autor (2010, p. 83) citando Domingues (2005, p. 13), a FNB teria sido o ensaio de um movimento comum maior com a liderança dos negros conscientes de sua posição ligada à barreira da cor. Assim, após ter convivido com o branco e ter sido rejeitado, originou-se no afrodescendente uma consciência racial, fazendo com que este procurasse se mobilizar com o fim de ascender socialmente e desfrutar de seus direitos como um indivíduo.

No Ceará, região que possui uma cultura marcada pela resistência negra, os movimentos sociais também tiveram enorme relevância, embora muitos historiadores ainda não tenham dado o merecido destaque às articulações das organizações afrodescendentes, sendo estes constantemente ocultados dos relatos e das memórias da formação histórica do Estado cearense.

Um dos acontecimentos pertinentes na história do Ceará que envolve o protagonismo de um homem negro foi muito bem recordado pela CEAFRO (2009, p. 05) que em seus dizeres, retorna ao ano de 1881, época em que transcorreu o evento marcado pela interrupção do desembarque de africanos escravizados em seus portos, comandado por Francisco José do Nascimento que passou a ser conhecido como Dragão do Mar - também é o nome do maior centro cultural da capital do Ceará. Contudo, sua origem africana é ordinariamente omitida pela história oficial.

Neste sentido, a CEAFRO (2009, p. 05-06) ainda expõe que analisando o campo da memória entrecruzando com o da cultura, também é representativo as narrativas através dos maracatus sobre a resistência negra. Essas manifestações são divididas politicamente em duas fases. A primeira, entre o fim da década de 70 e início da de 80, em que o Movimento Negro desponta junto aos outros movimentos populares urbanos, como exemplo: o Maracatu Nação Iracema criado em 1982, obtendo somente em 2002, o registro jurídico como Associação Cultural. Já a segunda fase, a do presente, trata-se do reconhecimento de terras quilombolas, surgimento de um organismo de promoção da igualdade e de políticas públicas. É possível 
citar o Quilombo de Alto Alegre, iniciado com a fuga do escravo Negro Cazuza de um navio ancorado na Barra do Ceará, em Fortaleza, e sua chegada a essa região. Tal associação obteve o certificado de reconhecimento concedido pela Fundação Cultural Palmares em 2005 após o processo de mobilização da comunidade iniciado no fim dos anos 90 .

Desta maneira, os movimentos sociais negros começam a construir em seus integrantes a formação de suas próprias identidades para lutar contra a invisibilidade que os atingem. Ao passo que os movimentos sociais negros se desenvolvem, as organizações feministas também. Doravante, surge a militância feminina negra.

[...] o processo de enegrecimento do feminismo é resultado de uma dialética que de um lado promove e do outro lado [...] exige o reconhecimento da diversidade e desigualdade existentes entre essas mesmas mulheres e a afirmação das mulheres em geral como novos sujeitos políticos. Em virtude disso [...] um feminismo negro, elaborado em estruturas latino-americanas, como exemplo de sociedades pluriculturais, multirraciais e racistas, tem como princípio articulador o racismo e seu impacto junto às relações de gênero. Isto significa [...] que o racismo demarca a própria hierarquia de gênero nesses modelos de sociedades. [...] A unidade na luta das mulheres não depende somente da aptidão de superar as desigualdades formadas pela histórica hegemonia masculina, mas requer, igualmente, a superação de ideologias complementares desse sistema opressivo, sendo nesse caso o racismo (CARNEIRO, 2003, p. 51-52).

Assim, as mulheres negras não precisam apenas superar a hegemonia masculina, mas também o racismo. Com isso, o movimento feminista provocou todo um debate político acerca de temáticas novas, como: a sexualidade, a violência e os direitos reprodutivos, segundo Joelma Gentil do Nascimento (2012, p. 23) citando Gonzalez (2011, p. 12-13). É dessa forma que ocorre uma ruptura do pensamento de que apenas os homens são naturalmente líderes das organizações. Assim, a resposta para as mulheres negras terem avançado politicamente foi "a consciência da 
importância de sua atribuição na história e terem mostrado situações de conflito e exclusão" (RIBEIRO, 1998, p. 198 apud NASCIMENTO, J., 2012, pag. 55). O mesmo autor (2012, p. 55) afirma ainda que os muitos embates travados pela feminitude afrodescendente junto aos movimentos sociais, tinha como tema central a invisibilidade. Esses movimentos buscavam, na realidade, serem notados. Precisavam serem vistos para mudar a realidade em que viviam.

É impensável desconsiderar a época de 1980 como os anos dourados do debate político sobre a sujeição feminina no Brasil, assim como de um momento de grandeza do idealismo feminista. Por exemplo, em 1988, surgiu no Brasil um dos principais grupos, o Geledés - Instituto da Mulher Negra, composto por mulheres que foram militantes no Coletivo de Mulheres Negras de São Paulo (NASCIMENTO, J., 2012, p. 60). Sobre esta época expõe o autor:

[...] o ano de 1988 foi de especial importância para as mulheres negras brasileiras, devido à intensidade de mobilização e discussão que seu tema lançou na sociedade, posto que encaminhou tanto um avanço no seu percurso organizativo, quanto indicou os diversos aspectos políticoideológicos que interpõe o Movimento de Mulheres Negras. A pesquisadora assegura ainda que em 1988 foram consolidadas vários Encontros Estaduais de Mulheres Negras. Em vista disso, consequentemente todas estas programações se direcionaram para o I Encontro Nacional de Mulheres Negras, que aconteceu de 02 a 04 de dezembro de 1988, na cidade de Valença, no Estado do Rio de Janeiro, com a participação de 450 mulheres negras, que representaram 17 estados do país, e ainda com a presença de muitas militantes do Movimento de Mulheres e representação de outros países como Estados Unidos, Equador e Canadá (CARNEIRO, 1993, p. 13 apud NASCIMENTO, J., 2012, p. 61).

Nesse diapasão, a cada debate, manifestação, greve ou protesto, direitos são conquistados e necessidades são notadas. Com os movimentos 
organizados pelas associações civis, as dificuldades são debatidas e, através de mais lutas, soluções são conquistadas.

A partir da militância feminina negra, suas integrantes passaram a ser sujeitos sociais com novos papéis. A partir da mudança do ambiente em que estão, a realidade é mudada. Se antes uma mulher negra não poderia pensar além de ser uma escrava, propriedade de um senhor, agora, as barreiras estão significativamente menores. Assim, as desigualdades vão sendo desconstruídas a partir das resistências das mulheres aos diferentes atos de abusos e opressões a que estão subordinadas. Logo, cada vez mais mulheres negras estão encontrando novas oportunidades de não estarem mais encurraladas ao ambiente doméstico e nem estarem submissas à ajuda econômica de um companheiro.

\section{Resultados e discussão}

Ao se debruçarem nas premissas específicas deste estudo, os pesquisadores direcionaram-se à sede do Grupo de Valorização Negra do Cariri. Porém, essa etapa só fora executada após esta pesquisa ter sido apreciada e aprovada pelo Comitê de Ética em Pesquisa, conforme parecer disponível na Plataforma Brasil.

O objetivo da visita de campo era entender como essa pessoa jurídica de temática negra promoveu a pressão popular e o combate à violência doméstica contra a população feminina preta e parda cratense no ano de 2016.

Para tal feito, inicialmente foram analisados os documentos que dizem respeito à constituição do Grupo, buscando melhor compreender seus objetivos e sua estruturação. Em seguida foram feitas entrevistas com dois integrantes importantes: uma das fundadoras do GRUNEC - a qual será identificada como entrevistada 1 - e a atual presidente do Grupo - que será identificada de entrevistada 2. 
Os termos utilizados para nomear as participantes da pesquisa é um modo de preservar suas identidades e, também, uma maneira de separar os seus discursos de modo a evitar que as falas de uma se misturem com as considerações de outra. Ainda é importante destacar que após a realização das entrevistas, ambas participantes assinaram o Termo de Consentimento Livre e Esclarecido, assentindo o uso de suas declarações para a elaboração deste estudo.

Ademais, foram feitas análises das atividades do grupo desenvolvida no ano de 2016. Nessa etapa da pesquisa, a entrevistada 2 guiou os pesquisadores em uma visita à página do Facebook do GRUNEC, uma vez que tal rede social funcionou como um diário que registrou as atuações dos membros durante aquele ano.

A partir disso, constatou-se que o Grupo de Valorização Negra do Cariri é uma pessoa jurídica de direito privado, sem fins lucrativos, constituída para realização de atividades de cunho cultural-educativo e de integração, articulação, proteção e representação, promovendo assim a dignidade e a inclusão da população negra e a valorização desta etnia no Cariri cearense, conforme dispõe o art. $1^{\text {a }}$ do Estatuto do GRUNEC.

Sua fundação remonta ao dia 21 de abril de 2001, momento em que um grupo de profissionais caririenses de diversas áreas do saber, embalados pela Conferência de Durban, se autoquestionaram sobre a participação do negro na formação do estado do Ceará, bem como idealizaram maneiras de combater o racismo e de promover a autoestima da população negra do Cariri. A partir dessas interrogações e de um conjunto de articulações desenvolvidas por esse agrupamento de pessoas, emergiu, assim, o GRUNEC.

Em se tratando dos objetivos do Grupo, é possível identificar, a partir do art. $3^{\circ}$ do seu Estatuto, que suas finalidades consistem em promover ações de implementação de políticas públicas voltadas à população negra; lutar pela valorização da etnia negra e contra todas as formas de opressão e exclusão social; combater práticas de racismo; garantir proteção legal, por 
meio de assessoria jurídica, às vítimas de racismo; construir com o povo negro o resgate de sua identidade e a cidadania sensibilizando-o para assumir sua negritude; entre outros escopos.

A partir de uma leitura das finalidades do GRUNEC, é possível inferir que não consta expressamente no seu rol de objetivos o combate à violência doméstica contra a mulher negra. No entanto, os escopos elencados são abrangentes e englobam essa pauta. Ademais, alguns fatores, em 2016, contribuíram para que o Grupo tivesse uma atenção especial ao enfretamento a esse tipo de violação de direitos.

Um desses motivos é o fato de o grupo em análise ter como principais mentoras mulheres de cor preta ou parda, sendo que, entre elas, está inclusa a principal liderança do GRUNEC que, em sua entrevista, também se identificou dentro desse perfil supramencionado. Em vista disso, é inegável que essas integrantes forneceram uma atenção especial aos casos que envolveram violência de gênero e de raça, afirmativa essa que poderá ser comprovada no momento em que se elencarem as atividades do Grupo.

Além disso, outra razão que justificou os esforços do GRUNEC no enfrentamento à violência contra a negritude feminina no seio familiar, foi o fato de o município de Crato-CE ter apresentado altos índices de ocorrência na delegacia especializada em apurar os crimes contra integridade física e psicológica da mulher.

Analisando esse fenômeno acima, a entrevistada 1 bem esclareceu que os dados que indicaram a crescente onda de violência contra a mulher no seu âmbito doméstico em 2016 foi preocupante e despertou a atenção do GRUNEC. Entretanto, apesar de a experiência demonstrar que a mulher negra é a maior vítima de violência familiar, os órgãos públicos de Crato$\mathrm{CE}$ - como delegacias e hospitais - não registraram a cor da pele da vítima ao efetuarem seus atendimentos. A consequência disso é uma total desinformação sobre a quantidade de mulheres negras que enfrentam essa dura realidade naquele município. 
Em busca de combater essa invisibilidade proporcionada pelo Estado, bem como enfrentar esse fenômeno violento que atinge mulheres negras da população cratense, o GRUNEC, enquanto organização civil de temática negra, articulou-se por meio de passeatas, reuniões, marchas, formações, rodas de conversas, cine debates, intervenções em espaços públicos etc. Dentre essas atividades supracitadas, algumas merecem ênfase em razão de sua pertinência e de seu impacto na sociedade. Inclusive, foram essas notáveis articulações que tornaram o ano de 2016 o recorte temporal desta investigação científica.

A primeira grande ação protagonizada a ser mencionada foi a participação do GRUNEC, conjuntamente com outros órgãos, em um acontecimento que ficou popularmente conhecido como o "caso Rayane". Segundo a entrevistada 1 , esse fato de grande repercussão na região no Cariri sucedeu quando, no dia 19 de março de 2016, a jovem Rayane Alves Machado fora raptada, sendo seu ex-companheiro apontado como principal suspeito de seu desaparecimento. Após 3 meses de busca, o então indiciado fora encontrado e testemunhas oculares confirmaram que o mesmo havia sequestrado, assassinado a facadas e ocultado o cadáver da jovem.

Durante esses 3 meses, o Grupo de Valorização Negra do Cariri desempenhou um papel de suma importância no transcorrer do caso, uma vez que forneceu todo o amparo à família da vítima; pressionou as autoridades competentes por meio de várias mobilizações; e fomentou, a partir desse crime, o debate acerca da violência contra a mulher negra nas relações privadas. Para a entrevistada 1 , a jovem vítima, que tinha a raça negra, tornou-se um símbolo de luta naquele ano de 2016. A indagação “cadê Rayane?" tornou-se um grito de guerra que ultrapassou o desfecho do crime e representou a luta para por fim a agressões de gênero/raça.

Além desse caso, é pertinente expor um conjunto de articulações feitas pelo Grupo no então presídio feminino e no Centro de Atenção Psicossocial (CAPS), ambos no município de Crato-CE. Para a entrevistada 2, acompanhar as mulheres que se encontravam nessas duas instituições é 
de grande pertinência e revela uma face da violência de gênero pouco conhecida pelo senso comum.

Para ela, a violência de gênero afeta bruscamente a realidade das mulheres a ponto de as consequências se tornarem catastróficas. Nos presídios femininos não é raro encontrar uma condenada que praticou algum delito em desfavor de um ente familiar em resposta à violência sofrida diariamente em sua relação privada. Da mesma forma, não há dificuldades de se identificar nos CAPS mulheres que desenvolveram doenças mentais em razão de um sofrimento psicológico oriundo de violência de gênero. Portanto, para entrevistada 2, ocupar esses espaços, dar amparo a essas mulheres e buscar entender esse fenômeno é uma forma de enfretamento ao machismo e ao racismo que assolam a realidade da feminitude negra do município de Crato.

Ademais, é de grande relevância destacar o evento anual intitulado "Artefatos da Cultura Negra" que é produzido pelo o GRUNEC em parceria com instituições de ensino superior da região do Cariri. Esse acontecimento de cunho científico e cultural, além de promover insignes debates e palestras concernentes aos temas de raça e de gênero, se destaca também por trazer uma feira regional em que mulheres expõem para venda seus objetos artesanais.

Como bem recordou a entrevistada 2, as relações baseadas em violência se perduram por muito tempo principalmente em razão de as mulheres, em especial as negras, ainda dependerem de seus companheiros para o seu sustento e de seus filhos. Logo, a feira de artesanato exposta no Artefatos da Cultura Negra comemora a autonomia financeira das mulheres negras artesãs e contribui para divulgação de seus trabalhos, representando, assim, mais uma atuação no combate a violência contra a mulher afrodescendente em sua esfera familiar.

Ao final, ambas as entrevistadas concordaram que, apesar do grande esforço de todos os integrantes, o Grupo de Valorização Negra do Cariri ainda não atingiu o objetivo de extinguir, totalmente, a violência contra a 
mulher negra em âmbito doméstico no município de Crato-CE. Ainda frisaram que para atingir esse resultado é necessário enfrentar complexas mazelas envolvendo a quebra do machismo e do racismo e que, suas esperanças estão depositadas nas lutas das futuras gerações.

No entanto, ressalvaram que conquistas importantes estão sendo obtidas por meio da atuação do Grupo e encerraram evidenciando que o protagonismo do GRUNEC melhoraria relevantemente se obtivessem um maior número de membros efetivos, se aprimorassem os portais de comunicação que o Grupo possui com a sociedade cratense e se os membros pudessem ter como fonte de renda os serviços prestados ao GRUNEC, uma vez que nenhum dos integrantes é remunerado por qualquer atividade praticada em prol do Grupo.

\section{Considerações finais}

Em face ao que fora apresentado, viu-se que esta pesquisa se ateve ao ano de 2016, atestando o quão o tema sobre a violência doméstica e familiar contra a mulher negra é atual. Também ficou claro que a realidade em que esta forma de violência se insere, reflete toda a historicidade em que o racismo e patriarcalismo se sustentaram.

Com isso, foi possível constatar que a construção da ideia de racismo desde a valorização negativa que a cor preta representava aos povos indoeuropeus e que foi se moldando com o tempo e o desenvolvimento da ideia de que o ser feminino era inferior ao ser masculino desde as primeiras histórias da humanidade até o estágio em que se apresenta hoje, mostram como essa parcela da população ainda precisa resistir a uma carga prédeterminada constituída historicamente.

Ademais, ao passo em que a população afrodescendente é rejeitada devido a sua cor, surgem obstáculos em seu desenvolvimento, tanto intelectual quanto econômico. Juntando-se a cor negra e o gênero feminino, 
tal desenvolvimento diminui ainda mais, resultando em mulheres negras com baixa escolaridade e subordinadas aos seus companheiros.

É nessa realidade que a violência doméstica e familiar ganha seu espaço, uma vez que o homem sabe que à mulher afrodescendente existem poucas alternativas. Nesse diapasão, para o combate à violência doméstica e familiar, a Lei 11.340/06 (Lei Maria da Penha) surgiu, apresentando em sua redação medidas para prevenção, assistência e proteção à feminitude que sofre violência. Assim, se a mulher negra é quem tem mais dificuldade em ter autonomia e se libertar do ambiente doméstico violento, é esta que acaba por se beneficiar mais da supracitada lei, pois é ela quem mais sofre a espécie de violência ora estudada.

Foi elucidado, também, que os movimentos sociais negros têm bastante relevância na luta para a obtenção de direitos de seus integrantes. Devido a rejeição que sofreu do branco, surgiu no afrodescendente uma consciência racial com o objetivo de ascender socialmente, e de combater a invisibilidade que sofria.

Os movimentos sociais desenvolvidos pela feminitude negra também tinham como tema central a invisibilidade, precisavam que fossem vistas para que notassem seus problemas. Assim, as desigualdades vão sendo desconstruídas a partir das resistências das mulheres à realidade em que estão inseridas desde suas origens.

Outrossim, revelou-se que o Grupo de Valorização Negra do Cariri é uma pessoa jurídica sem fins lucrativos cujo principal objetivo é a valorização da etnia negra do povo Caririense, ao mesmo tempo em que promovem o embate às diversas manifestações de exclusão e de opressão social desses indivíduos.

Além disso, constatou-se que não está incluso expressamente no rol de finalidades do Grupo o combate à violência contra a mulher negra no seio doméstico, todavia, os escopos elencados em seu Estatuto possuem um caráter abrangente, englobando, também, essa pauta. De resto, o fato de 2016 ter sido marcado pela violência de gênero e de raça, assim como a forte 
presença da figura feminina preta e parda em cargos de liderança dentro do GRUNEC, fez com que, no ano delimitado, essa questão se tornasse a prioridade nas articulações de seus integrantes. Empós, foram elencadas as mais relevantes atividades do Grupo, deixando enfático o protagonismo do mesmo no "caso Rayane", nas ações efetivadas no presídio feminino e no CAPS de Crato-CE e nas atividades no evento do Artefatos da Cultura Negra.

Portanto, a partir da experiência do GRUNEC foi possível compreender melhor o papel das organizações civis de temática racial no combate a violência doméstica contra a mulher negra.

Essas organizações são responsáveis por tentar dar visibilidade, combater a opressão e a exclusão social aos quais essas vítimas estão sujeitas. Assim, é necessário refletir e ampliar as discussões sobre associações civis que objetivem findar com a negligência histórico-social contra as mulheres negras vítimas de violência em seu âmbito privado, vez que esse problema não é só constatável apenas no município de Crato-Ce, mas se apresenta em todo Brasil.

Logo, a experiência do GRUNEC deve servir de espelho para todo o território nacional, para que seja possível construir novos movimentos civis que estejam cientes do contexto social e da situação de violência contra mulheres pretas/pardas, para que novas atividades de apoio, de promoção financeira, de proteção e de manifestações sejam realizadas, visando combater e expor a vulnerabilidade que as vítimas negras estão sendo submetidas em seus lares.

\section{Referências}

CARNEIRO, Sueli. Enegrecer o feminismo: a situação da mulher negra na América latina a partir de uma perspectiva de gênero. In: ASHOKA EMPREENDEDORES SOCIAIS; TAKANO CIDADANIA (Orgs.). Racismos contemporâneos. Rio de janeiro: Takano Editora, 2003. 
CEAFRO. Informe sobre políticas e movimentos negros no Ceará. 2009. Disponível em $<$ https://slidex.tips/download/informe-sobre-politicas-emovimentos-negros-ceara>. Acesso em: 18 jun. 2018.

COIMBRA, Patrícia Carla dos Santos. Direito das mulheres pós constituição: um estudo descritivo. Brasília: Cefor, 2011. Disponível em: $<\underline{\text { http://bd.camara.gov.br/bd/handle/bdcamara/9148> }}$. Acesso em: $10 \mathrm{de}$ dezembro de 2017.

NASCIMENTO, Abdias do. O genocídio do negro brasileiro: processo de um racismo mascarado. Rio de Janeiro: Paz e Terra S/A, 1978.

NASCIMENTO, Joelma Gentil do. Memórias organizativas do movimento negro cearense: algumas perspectivas e olhares das mulheres militantes na década de oitenta. Fortaleza: UFC, 2012.

OLIVEIRA, Glaucia Fontes de. Violência de gênero e a lei Maria da Penh a. Brasília: Conteúdo Jurídico, 2010. Disponível em: $<$ http://www.conteudojuridico.com.br/?artigos\&ver=2.29209>. Acesso em: 11 de dezembro de 2017.

PEREIRA, Amilcar Júnior. "O Mundo Negro": a constituição do movimento negro contemporâneo no Brasil (1970-1995). Niterói: UFF, 2010.

PIOVESAN, Flávia; PIMENTEL, Sílvia. A Lei Maria da Penha na perspectiva da responsabilidade internacional do Brasil. In: CAMPOS, Carmem Hein de (Org.). Lei Maria da Penha comentada em uma perspectiva jurídico-feminista. Rio de Janeiro: Lumen Juris, p. 101-116, 2011.

PRIORE, Mary Del. Conversas e histórias de mulheres. 1 ed. São Paulo: Planeta, 2013.

PRIORE, Mary Del; BASSANEZI, Carla. História das mulheres no Brasil. 7 ed. São Paulo: Contexto, 2004.

SAFFIOTI, Heleieth Iara Bongiovani.Ontogênese e filogênese do gênero: ordem patriarcal de gênero e a violência masculina contra mulheres. Brasil: FLACSO, 2009.

SANTOS, Gislene Aparecida dos. A invenção do "ser negro": um percurso das idéias que naturalizam a inferioridade dos negros. São Paulo: Educ/Fapesp; Rio de Janeiro: Pallas, 2005.

SECRETARIA ESPECIAL DE POLÍTICAS PARA AS MULHERES. Balanço $1^{\circ}$ SEMESTRE 2016. Brasília, 2016. Disponível em: $<$ http://www.spm.gov.br/balanco180 2016-3.pdf $>$. Acesso em: 18 jun. 2018. 
SÍNTESE DE INDICADORES SOCIAIS: UMA ANÁLISE DAS CONDIÇÕES DE VIDA DA POPULAÇÃO BRASILEIRA. Rio de Janeiro: IBGE, 2017.

WALLER, Eliane. Vestidos e mordaças: representações da opressão feminina na literatura brasileira nos séculos XIX e XX. Rio de Janeiro: UERJ, 2008.

Recebido em fevereiro de 2019.

Aprovado em abril de 2019. 